Roberto Remedi, De "militante" a "intelectual": Francisco René Santucho en el discurso de las ciencias humanas de los últimos quince años en Argentina / From "militant" to "intellectual": Francisco René Santucho in the discourse of the human sciences over the last fifteen years in Argentina, Revista Izquierdas, 27, abril 2016, ISSN 0718-5049, pp. 256-271

\title{
De "militante" a "intelectual": Francisco René Santucho en el discurso de las ciencias humanas de los últimos quince años en Argentina
}

\section{From "militant" to "intellectual": Francisco René Santucho in the discourse of the human sciences over the last fifteen years in Argentina}

\author{
Roberto Antonio Remedi*
}

\footnotetext{
* Argentino. Licenciado en Comunicación Social. Auxiliar Docente Graduado en la Carrera de Licenciatura en Ciencias de la Comunicación, Facultad de Filosofía y Letras, Universidad Nacional de Tucumán. Doctorando en Antropología, Programa de Doctorado de la Facultad de Filosofía y Letras, Universidad de Buenos Aires. Mi plan de tesis versa sobre las "Formas, momentos y espacios de enunciación de la alteridad india/indígena en la crítica cultural de Francisco René Santucho (1953-1963): usos sociales del indoamericanismo y del mestizaje en Santiago del Estero a mediados de siglo XX. El trabajo que aquí presento (destinado a evaluar los aportes de la literatura científica existente sobre el caso objeto de estudio) forma parte de esa investigación más amplia, antonioremedi@ yahoo.com.ar
} 
Roberto Remedi, De "militante" a "intelectual": Francisco René Santucho en el discurso de las ciencias humanas de los últimos quince años en Argentina / From "militant" to "intellectual": Francisco René Santucho in the discourse of the human sciences over the last fifteen years in Argentina, Revista Izquierdas, 27, abril 2016, ISSN 0718-5049, pp. 256-271

\section{Resumen:}

Francisco René Santucho (1925-1975) es un crítico de la provincia de Santiago del Estero (Argentina). En 1956 edita Dimensión. Revista de cultura y crítica y en 1961 anima la formación del Frente Revolucionario Indoamericano Popular. Fusiona marxismo e indigenismo, cuestionando el relato hegemónico de la nación en el país, porteñocéntrico, europeizante. Este artículo examina la forma predominante cómo fue abordado en el discurso de las ciencias humanas durante los últimos quince años en el contexto de Argentina.

Palabras clave: Francisco René Santuchomilitante- intelectual- crítico

\begin{abstract}
:
Francisco René Santucho (1925-1975) is a critic from Santiago del Estero. In 1956 he publishes Dimensión. Revista de cultura y crítica and in 1961 organizes the Frente Revolucionario Indoamericano Popular. In this period the critic fuses marxism and indigenouness, remarking the hegemonic identifiable statement in the eurocentric country. This article examines the predominant form how Santucho it has been studied in the discourse of the human sciences over the last fifteen years in the context of Argentina.
\end{abstract}

Key words: Francisco René Santuchomilitant- intellectual- critic

Recibido: 30 octubre 2015

Aceptado: 10 diciembre 2015

\section{Introducción}

En Argentina, el estudio científico sobre los procesos de renovación cultural de las décadas de 1960 y 1970 atravesó un acelerado desarrollo desde el cambio de siglo. En ese marco se abordaron algunos aspectos de la vida de Francisco René Santucho (1925-1975). Se trata de un crítico de la provincia de Santiago del Estero. En 1956 edita Dimensión. Revista de cultura y crítica y en 1961 anima la formación del Frente Revolucionario Indoamericano Popular. Fusiona marxismo e indigenismo $-\mathrm{o}$ como él prefería decir, "indoamericanismo"-, cuestionando el relato hegemónico de la nación en el país, porteñocéntrico, europeizante. Durante la década de 1990 y la primera del nuevo milenio su figura atrajo el interés tanto del discurso periodístico como testimonial ${ }^{1}$. Pero en el tramo de los últimos quince años proliferaron trabajos que volvieron sobre el caso desde el ámbito de las ciencias humanas. Entonces he creído oportuno examinar la forma predominante cómo fue abordado en este preciso espacio. En este lapso, predominó inicialmente la preocupación por indagar sobre las formaciones en las que Santucho participó. Luego

\footnotetext{
${ }^{1}$ Respectivamente: María Seoane, Todo o nada. La historia secreta y la historia pública del jefe guerrillero Mario Roberto Santucho, Editorial Sudamericana, Buenos Aires, [1991] 2009 y Blanca R. Santucho, Nosotros, los Santucho, Buenos Aires, el autor, 2009; Luis H. Santucho, "Francisco René Santucho", La unidad indoamericana, Buenos Aires, Populibros, 2009, 7-27; Daniel De Santis, La historia del PRT-ERP: por sus protagonistas, Temperley-Estación Finlandia, A formar filas-Editora guevarista, 2010. Estos géneros discursivos han quedado excluidos de la revisión. Entiendo que persiguen su legitimidad usando procedimientos distintos al discurso científico.
} 
Roberto Remedi, De "militante" a "intelectual": Francisco René Santucho en el discurso de las ciencias humanas de los últimos quince años en Argentina / From "militant" to "intellectual": Francisco René Santucho in the discourse of the human sciences over the last fifteen years in Argentina, Revista Izquierdas, 27, abril 2016, ISSN 0718-5049, pp. 256-271

algunas miradas comenzaron a deslizarse sobre su persona en singular. Asimismo, en un principio llamó la atención su perfil "militante" o su praxis "política". Pero más recientemente empezó a adquirir prioridad la descripción de su faceta "intelectual" o su intervención en la "cultura". Inicialmente, la historiografía se constituyó en la disciplina pionera en delinear un conjunto de preguntas acerca de Santucho. Pero desde hace pocos años la perspectiva poscolonial, la sociología de la cultura y la crítica cultural introdujeron nuevos interrogantes. No obstante estas trasformaciones, aún cuesta reconocer en Francisco René la figura del crítico en sentido profesional como así también elaborar una estrategia de análisis pertinente. Sus intervenciones en el contexto de la tradición crítica se incluyen sólo tácitamente o es objeto de estudio secundario. Ciertamente, no han faltado trabajos donde se hayan hecho referencias a su impronta "crítica", tornando este aspecto un punto central. Pero ha prevalecido implícitamente una concepción instrumental del discurso como soporte absolutamente trasparente. Así, por ejemplo, cuando se hace referencia a su adscripción "indoamericanista" y su reivindicación de las tradiciones precolombinas, la "raza" y la "etnicidad" aparecen en los análisis como objeto tácito o alternativamente como categorías genéricas o invariables. Rara vez se dice qué tipo de clasificaciones son, ni se describe la específica forma y el preciso contexto de enunciación, eludiendo así la historicidad de las adscripciones/discursos étnico-raciales. El relato que sigue da cuenta de este balance de manera detallada, exponiendo al final algunas orientaciones que redireccionen la búsqueda. El examen se lleva a cabo recurriendo a la noción de polifonía de Mijaíl Bajtín. Como el crítico ruso entiendo que los enunciados discursivos están constituidos por múltiples voces y estructuras de significados en virtud de específicos contextos comunicativos ${ }^{2}$.

\section{Perspectivas historiográficas}

Han sido los historiadores interesados en la historia reciente los pioneros en elaborar las primeras aproximaciones científicas sobre el caso. Aunque en estos abordajes la figura de Francisco René se ubica en un segundo plano. Por el contrario es su hermano Mario Roberto quien ha concitado mayor preocupación. Este desbalance tiene lugar dentro de una política conceptual preocupada por reconstruir el perfil "político" o "militante" de quienes activaron en las luchas revolucionarias de la segunda mitad de siglo XX. A comienzos de la primera década del nuevo milenio un análisis propuso "considerar el desarrollo del militante guerrillero en el proceso histórico de cambio", tomando el caso del PRT-ERP (Partido Revolucionario de los Trabajadores-Ejército Revolucionario del Pueblo), facción armada de la organización política que Mario Roberto Santucho lideró hacia $1970^{3}$. Ya a inicios de la segunda década existió el interés por comprender aspectos más específicos,

\footnotetext{
${ }^{2}$ Mijaíl Bajtín, Estética de la creación verbal, Buenos Aires, Siglo XXI Editores, 2002, 274, $281,285$.

${ }^{3}$ Según la hipótesis que guía la indagación, "la guerrilla en la Argentina fue un producto del proceso histórico argentino y surgió estrechamente ligada al movimiento social. En este sentido, la guerrilla se nutrió de todos los sectores sociales de la población y se desarrolló en contacto con los trabajadores y los sectores más pobres de la sociedad argentina". Pablo Pozzi, Por las sendas argentinas: PRT-ERP, la guerrilla marxista, Buenos Aires, Imago Mundi, 2004, 31.
}

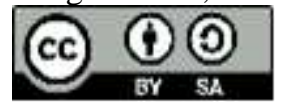


Roberto Remedi, De "militante" a "intelectual": Francisco René Santucho en el discurso de las ciencias humanas de los últimos quince años en Argentina / From "militant" to "intellectual": Francisco René Santucho in the discourse of the human sciences over the last fifteen years in Argentina, Revista Izquierdas, 27, abril 2016, ISSN 0718-5049, pp. 256-271

focalizando la mirada concretamente sobre el "proceso de construcción identitaria de la organización y la subjetividad colectiva en él implicada"4. En ambos casos, la importancia atribuida al rol que desempeñó Mario Roberto durante la etapa de radicalización del FRIP adquiere prioridad. Se destaca su influencia en el acuerdo de trabajo conjunto entre el FRIP y el PO (Palabra Obrera, organización trotskista de nivel nacional) y la posterior formación del Partido Revolucionario de los Trabajadores (1964 y 1965, respectivamente). En estos relatos, Francisco René, sus particulares ideas y proyectos, constituyen un "antecedente" o aspecto "preliminar" de la historia posterior.

Al final de la primera década distintos estudios trataron de revertir el lugar secundario otorgado a Santucho en la historia reciente. El Diccionario biográfico de la izquierda argentina. De los anarquistas a la "nueva izquierda" [1870-1976], propuso oportunamente llenar "un vacío en la historiografía argentina". Según esta perspectiva no se trata de "reducir el pensamiento histórico a la singularidad de cada individuo, sino de construir retratos colectivos enriquecidos y complejizados a partir del estudio metódico de los itinerarios individuales"6. Pues resulta problemático "estudiar seriamente los movimientos sociales y las izquierdas argentinas (...) sin conocer el perfil biográfico y el itinerario político de al menos sus principales animadores". La categoría "militantes" adquiere aquí el sentido que Jean Maitron dio al término oportunamente, refiriendo a hombres y mujeres comprometidos en una acción que aspira a lograr mayor justicia social y mayor libertad ${ }^{8}$. Así, se reconstruyen sus biografías siguiendo la noción de "itinerarios", "como caminos abiertos a un cierto juego de probabilidades, donde en cada corte o en cada nudo histórico se redefinen las chances vitales". . En este marco se ofrece un relato sobre Francisco René Santucho ${ }^{10}$. Paradójicamente, en un trabajo destinado a construir "retratos colectivos" a partir de "itinerarios individuales" queda fuera de foco (por dar prioridad a la amplitud de aspectos biográficos, los espacios de acción militante y sus avatares) la actividad que el propio objeto eligió como forma privilegiada de praxis: la crítica como disciplina.

Ya en un contexto de discusión promovido por la historia intelectual tuvieron lugar en los primeros años de la segunda década dos artículos dedicados a reflexionar sobre distintos emprendimientos de Santucho. Ambos fueron incorporados al dossier "Santiago del Estero: bibliotecas, grupos, revistas, librerías" dedicado a la "Historia del libro, la

\footnotetext{
${ }^{4}$ Vera Carnovale, Los combatientes. Historia del PRT-ERP, Buenos Aires, Siglo XXI Editores, 2011, 11-12.

5 Horacio Tarcus, "Introducción”, Diccionario biográfico de la izquierda argentina. De los anarquistas a la “nueva izquierda” (1870-1976), Horacio Tarcus (dir.), Buenos Aires, Emecé Editores, 2007, XI-XXX.

${ }^{6}$ Tarcus, op.cit., XV.

${ }^{7}$ Tarcus, op.cit., XVII.

${ }^{8}$ Tarcus, op.cit., XX.

${ }^{9}$ Con este enfoque se trataría de “escapar a lo que Michel Verret denominó la lógica «lineal perspectivista» por la cual el militante o la organización a la que perteneció tejerán el relato de su vida como «trayectoria», destacando invariablemente tópicos como su «temprana vocación» por la justicia o la libertad; o la construirán como «carrera», destacando los éxitos que le permitieron pasar de una a otra etapa (y seguramente silenciando los fracasos)", Tarcus, op.cit., XXVII.

${ }^{10}$ Laura Ehrlich, "Santucho, Francisco René", Diccionario biográfico de la izquierda argentina. De los anarquistas a la "nueva izquierda” (1870-1976), Horacio Tarcus (dir.), Buenos Aires, Emecé Editores, 2007, 605-608.
}

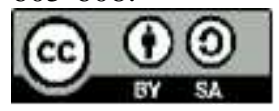


Roberto Remedi, De "militante" a "intelectual": Francisco René Santucho en el discurso de las ciencias humanas de los últimos quince años en Argentina / From "militant" to "intellectual": Francisco René Santucho in the discourse of the human sciences over the last fifteen years in Argentina, Revista Izquierdas, 27, abril 2016, ISSN 0718-5049, pp. 256-271

edición y la lectura en la Argentina" (Políticas de la Memoria 14). En "Apuntes sobre la revista, el grupo y la librería Dimensión. La cultura como incitación", se propone "reconstruir la experiencia desarrollada por Dimensión en tanto productor cultural" ". Aun cuando Francisco René no es el objeto de estudio sino los distintos ámbitos organizativos que él mismo propició, no deja de reconocerse su centralidad: "A través de sus escritos, editoriales y artículos, el perfil regional de Dimensión tomará identidad y se definirá sobre la base del indoamericanismo" "12. La prioridad conceptual otorgada a la categoría "productor cultural" del crítico neomarxista inglés Raymond Williams hace que el énfasis de la indagación recaiga en la revista y las distintas actividades que se generaron a su alrededor. Pero la apertura de la mirada paradójicamente termina cerrando la búsqueda. Queda fuera del objeto la actividad que articuló y dio sentido a las diversas "producciones culturales" que Santucho promovió, esto es, la praxis crítica como particular oficio o hacer específico de la "producción cultural".

Por su parte, el artículo "Santiago del Estero 1956-1962. Dimensión, una revista de cultura y crítica", describe el proyecto editorial, problematizando dos aspectos ${ }^{13}$. El emprendimiento gráfico es considerado comúnmente un capítulo en la formación de la nueva izquierda argentina y su trágica derrota, "como una anticipación de lo que finalmente sucedió"14. Asimismo, el contenido de Dimensión es asimilado al discurso indoamericanista de su director. Pero "la nota característica de la mayoría de los trabajos publicados (inclusive los de F. R. Santucho) es la preocupación por el desarrollo institucional-educativo, cultural, intelectual y artístico de la provincia de Santiago del Estero en particular, y de las provincias norteñas del interior de nuestro país, en general" ${ }^{15}$. Dentro de esta lectura, "Dimensión parece más el resultado de esa preocupación (provincial y periférica) convertida en urgencia, que un órgano del discurso indoamericanista; más profesado por Santucho que por el resto de los autores"16. Ciertamente, para algunos artífices de la revista y de las actividades que se desarrollaron a su alrededor existió una "razón trasformadora". Lo cual, podría decirse, "representa la antesala de la creación del Frente Revolucionario Indoamericano y Popular". Sin embargo, Dimensión "defiende la autonomía del trabajo intelectual respecto de la militancia propiamente política"17. El artículo tiene el mérito de llamar la atención sobre la necesidad de deslindar metodológicamente el discurso de Santucho con relación al texto de Dimensión e interrogar la especificidad de una revista "cultural" en el marco de las preocupaciones de su propio tiempo más que a la luz de los acontecimientos históricos posteriores. No obstante, queda pendiente el análisis de la forma cómo se consumó en la práctica de la escritura "la crítica de la cultura" y "la autonomía del trabajo intelectual" como así también una discusión

\footnotetext{
${ }^{11}$ César D. Gómez, “Apuntes sobre la revista, el grupo y la libraría Dimensión. La cultura como incitación”, Políticas de la memoria 14, Buenos Aires-Argentina, verano de 2013-2014, 118-123.

${ }^{12}$ Gómez, op. cit., 120, destacado en el original.

13 Ana B. M. Trucco Dalmas, "Santiago del Estero 1956-1962. Dimensión, una revista de cultura y crítica", Políticas de la memoria 14, Buenos Aires-Argentina, verano de 2013-2014, 124-129.

${ }^{14}$ Trucco Dalmas, op. cit., 125.

15 Trucco Dalmas, op. cit., 127.

16 Trucco Dalmas, op. cit., 127.

${ }^{17}$ Trucco Dalmas, op. cit., 127.

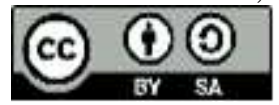


Roberto Remedi, De "militante" a "intelectual": Francisco René Santucho en el discurso de las ciencias humanas de los últimos quince años en Argentina / From "militant" to "intellectual": Francisco René Santucho in the discourse of the human sciences over the last fifteen years in Argentina, Revista Izquierdas, 27, abril 2016, ISSN 0718-5049, pp. 256-271

conceptual sobre la manera pertinente de indagar este particular género discursivo y espacio de circulación de sentido.

\section{La mirada poscolonial}

De modo que bien entrada la segunda década del nuevo milenio se asiste a una modificación en el espacio de interrogación sobre Francisco René Santucho. Su figura es desplazada del terreno de la "militancia" al ámbito "intelectual". Pero en esta misma dirección ya había existido un deslizamiento significativo poco tiempo antes. La mirada poscolonial entra en la escena a principios de esa década. Entones Santucho es ubicado dentro de un amplio espacio "dialógico" donde sus perfiles tanto de "militante" como de "intelectual" constituyen sólo dos aspectos entre otros. En "Añoranza y revolución. Lo indio, lo negro y lo cholo en lo «santiagueño», en el norte argentino", el autor propone "establecer un diálogo con un pensador, escritor y militante santiagueño poco conocido y mucho menos reconocido en los ámbitos académicos e intelectuales dominantes: Francisco René Santucho"18. La preocupación central del artículo no es su figura. El título del trabajo de hecho evita implicar a Santucho como "objeto". Más bien interesa inscribir sus pensamientos en torno a preocupaciones (más o menos) compartidas (como la vigencia de las tradiciones "indígenas"). A partir de esta premisa se toman algunos aportes de Francisco René para reflexionar sobre la relación entre "cuerpos, estéticas y movimientos sociales"19. En el análisis adquiere relevancia la forma estratificada y multitemporal de concebir las relaciones sociales y las distintas maneras de hacer con las cuales los grupos subalternos se procuran su continuidad. Según el estudio, las intervenciones del propio Santucho estaban comprometidas en complejas configuraciones discursivas y relaciones de poder: "La «Provincia» se puede ver en acción (sin crítica mediante) en el texto mismo de Francisco René El indio en la Provincia de Santiago del Estero (Santucho 1954); lo cual nos ubica performativamente en un mapa nacional. Y esto produce la apariencia de que en todo caso lo «indio» fuera pensado siempre encapsulado en el mapa provincial" ${ }^{\text {" }}$. Sin embargo, este comprometido emplazamiento discursivo no le imposibilitó identificar distintos modos de contrarrestar la dominación: "Francisco René reconoce en la mediación linguística una materia simbólica que se tiende subrepticiamente bajo el dominio colonial y nacional". Había observado, "De simple o compleja contextura, existió una integración cultural (indígena), cuyos vestigios nos llegan por conducto verbal del pueblo, en manifestaciones que encuadramos como folklóricas (la quichua, mitos, relatos, coplas), pervivencias mitológicas de herencia aborigen que particularizan el inconfundible tipismo de lo santiagueño (Santucho 1954)"21. En continuidad con esta interpretación se hace explícita la hipótesis en torno al tema del artículo. La puesta en escena de la añoranza (en las ceremonias, festividades y la vida cotidiana de los sectores populares) configura la semio-praxis con la cual los "santiagueños" (en tanto lugar de

\footnotetext{
18 José L. Grosso, “Añoranza y revolución. Lo indio, lo negro y lo cholo en lo «santiagueño», en el norte argentino", Páginas de cultura 6, Cali-Colombia, septiembre de 2011, 33.

${ }^{19}$ Grosso, op. cit., 33.

${ }^{20}$ Grosso, op. cit., 33.

${ }^{21}$ Grosso, op. cit., 34, las cursivas pertenecen a la transcripción. 
Roberto Remedi, De "militante" a "intelectual": Francisco René Santucho en el discurso de las ciencias humanas de los últimos quince años en Argentina / From "militant" to "intellectual": Francisco René Santucho in the discourse of the human sciences over the last fifteen years in Argentina, Revista Izquierdas, 27, abril 2016, ISSN 0718-5049, pp. 256-271

identificación colonial y republicano) evocan tácitamente relaciones negadas (lo "negro", lo "indio", lo "cholo"). La añoranza "opera emotivamente como poder-de-ausencia", configurando una particular economía crítica. Pues "lo que no ha llegado a la «identidad» es la fuerza negativa de lo «santiagueño»"22. En suma, se trata de un análisis de las relaciones y discursos sobre la alteridad étnico-racial en la sociabilidad históricocontemporánea de Santiago del Estero. Como he dicho, el texto no focaliza la atención sobre Santucho específicamente. Pero plantea de manera contundente la pertinencia del estudio de su producción desde una noción de discurso que tenga en cuenta el análisis de su particular materialidad, esto es, de las voces y poderes que lo configuran. Entre líneas surge la pregunta por qué Santucho, aun cuando elaboró una concepción estratificada de las creencias y las relaciones, destacó la "herencia indígena" en el "tipismo santiagueño", obviando la vigencia de otras tradiciones subalternizadas, y erigió al "indoamericanismo" en lugar positivo de identificación para una concepción teórica y organización política. No obstante el aporte claro y novedoso de este abordaje, se echa de menos un ajuste de cuentas con las ciencias antropológicas, considerando que este espacio disciplinar ha hecho objeto privilegiado de estudio las semejanzas y diferencias "culturales" y "biológicas" entre los conjuntos humanos. Con todo, a pesar del carácter sugerente del artículo, no parece haber llamado la atención de los estudiosos contemporáneos, a juzgar por la inexistencia de comentarios, en particular, de quienes se dedicaron a analizar la producción de Francisco René.

\section{Contribuciones de la crítica}

A tono con un creciente interés por reivindicar a Santucho en la escena "intelectual", los críticos también han intervenido para examinar precisamente sus aportes en el propio territorio de la disciplina. Es el caso de los tres estudios incluidos en la reciente edición facsimilar de la revista que dirigió Francisco René. En "Dimensión: el paso restante", la producción gráfica es caracterizada correctamente en el espacio de la crítica como ámbito profesional $^{23}$. Y el análisis gira en torno a los atributos del objeto en tanto escritura. Se identifica en efecto su preocupación central: "La crítica al proyecto de la inmigración". Luego sigue una descripción de la forma cómo el contenido de esa premisa se despliega: "La cosa está dicha con muchos tonos, y cuando la hipérbole absorbe la cuestión, enseguida aparece un pulso moderatista, acaso un poco dolorido, pues el énfasis profundo de la revista no oculta una confiante arrogancia ni un pudoroso tilde, que sin ser académico, se reserva la práctica del buen escribir" ${ }^{24}$. Por primera vez, Dimensión aparece retratada en el lugar dónde y en la forma cómo el proyecto editorial se instaló. Sin embargo, queda el interrogante acerca de por qué el cuestionamiento al modelo de nación inspirado en el progreso asumió diversos "tonos", y si ese estilo de escritura fue un simple recurso

\footnotetext{
${ }^{22}$ Grosso, op. cit., 34.

23 Horacio González, "Dimensión: el paso restante", Dimensión. Revista de cultura y crítica. Edición facsimilar, Santiago del Estero, Subsecretaría de Cultura de la Provincia de Santiago del Estero-Biblioteca Nacional de la República Argentina, 2012, 9-10.

${ }^{24}$ González, op. cit., 9.
} 
Roberto Remedi, De "militante" a "intelectual": Francisco René Santucho en el discurso de las ciencias humanas de los últimos quince años en Argentina / From "militant" to "intellectual": Francisco René Santucho in the discourse of the human sciences over the last fifteen years in Argentina, Revista Izquierdas, 27, abril 2016, ISSN 0718-5049, pp. 256-271

usado instrumentalmente o un modo a través del cual (y sin el cual) podía formularse esa precisa crítica.

El segundo artículo es "Dimensión y la relectura de la historia"25. Según se postula, la revista "encontró una forma específica de imbricar los temas y preocupaciones locales que se habían trabajado durante los años anteriores, y al mismo tiempo proponer su propia lectura de la historia" ${ }^{26}$. Estos temas y preocupaciones están materializados en los artículos del propio Santucho. Entre otros planteos se puede leer, por ejemplo, una reflexión "sobre las grandes formaciones culturales del período prehispánico que gravitaron sobre el norte de la Argentina" o "un ensayo sobre la actitud de los «indoamericanos» ante la universalización" 27 . De acuerdo con este análisis, "Las décadas siguientes confirmaron algunos de los argumentos que Santucho sostuvo en Dimensión. La subjetividad tomó forma como una categoría de las formas de ser humano; la identidad étnica también, no menos que el desafío global sobre el territorio local". Se sugiere, "El pensamiento de Francisco René Santucho alentó una «americanización» de las propuestas revolucionarias, y regionalizando sus contenidos" 28 . Sin duda el análisis acierta en destacar un aspecto que algunos observadores habían pasado por alto al examinar Dimensión y los textos de Santucho. A saber, la dimensión subjetiva y cotidiana en los que se sustentan los proyectos políticos y culturales. Sin embargo, la interrogación se detiene allí. Y al lector le queda la pregunta de por qué la "etnicidad" se constituyó en lugar de interpelación (y no otra clasificación como la "clase" o la "raza"), pero no se conformó finalmente en lugar de adscripción capaz de sostener las luchas revolucionarias del período inmediatamente posterior. El paso del Frente Revolucionario Indoamericano Popular al Partido Revolucionario de los Trabajadores lo confirma. Marca un cambio en la construcción del "sujeto político". En suma, este análisis pone a Dimensión y a Santucho de frente a la "subjetividad" más que implicados en ella.

En "Las intuiciones de un «cacique» del siglo XX. Apuntes sobre el pensamiento de Francisco René Santucho" se parte de una precisa caracterización ${ }^{29}$. El anacronismo o la desconfianza en el progreso es la forma que asume su cosmovisión. El intelectual santiagueño "asumirá de manera programática la cuestión indígena y su vínculo tormentoso con la modernidad colonial, en tiempos donde lo indio era considerado (incluso por las corrientes emancipadoras y de izquierda) factor inútil y retardatario" 30 . Como muchos intelectuales comprovincianos contemporáneos, Santucho se lanza al "rescate de las culturas originarias", pero su contribución "posee un tinte peculiar: de la crítica historiográfica a la lingüística, del análisis de la psiquis a la cuestión social, la geografía, la

\footnotetext{
${ }^{25}$ Alberto Tasso, "Dimensión y la relectura de la historia", Dimensión. Revista de cultura y crítica. Edición facsimilar, Santiago del Estero, Subsecretaría de Cultura de la Provincia de Santiago del Estero-Biblioteca Nacional de la República Argentina, 2012, 11-19.

${ }^{26}$ Tasso, op. cit., 12.

${ }^{27}$ Tasso, op. cit., 13.

${ }^{28}$ Tasso, op. cit., 18.

${ }^{29}$ Mario A. Santucho, "Las intuiciones de un «cacique» del siglo XX. Apuntes sobre el pensamiento de Francisco René Santucho", Dimensión. Revista de cultura y crítica. Edición facsimilar, Santiago del Estero, Subsecretaría de Cultura de la Provincia de Santiago del Estero-Biblioteca Nacional de la República Argentina, 2012, 21-35.

${ }^{30}$ Santucho, op. cit., 21, destacado en el original.
} 
Roberto Remedi, De "militante" a "intelectual": Francisco René Santucho en el discurso de las ciencias humanas de los últimos quince años en Argentina / From "militant" to "intellectual": Francisco René Santucho in the discourse of the human sciences over the last fifteen years in Argentina, Revista Izquierdas, 27, abril 2016, ISSN 0718-5049, pp. 256-271

memoria, la literatura, la política... en cada uno de estos territorios lo indio asoma como un desafío a develar y no como una identidad ya conformada"31. Ciertamente, el racismo es el eje de su proyecto intelectual y la crítica el ámbito de discusión. Hasta ahora nunca antes la observación había alcanzado este grado de formulación (aunque en el texto no aparezca dicho de manera contundente). Sin embargo, el trabajo no llega a dar cuenta por qué, en la construcción textual del debate, el cuestionamiento de las creencias sobre las diferencias "raciales" aparece tematizada en términos de diferencias "culturales". Asimismo, si el anacronismo como perspectiva abre una comprensión multitemporal y contingente de la historia y de las identificaciones, el planteo no puede responder por qué la posición de Santucho es explícitamente indoamericanista y no indo-afro-americanista, siendo que las tradiciones africanas constituyen un legado de la modernidad colonial. Finalmente, queda la sensación de que las principales afirmaciones sobre el pensamiento de Santucho son más el producto de una proyección de las concepciones teóricas actuales del investigador que un esfuerzo por comprender los diálogos analizados en tanto formaciones históricas.

\section{Aportes de la sociología de la cultura}

De los primeros años de la segunda década del nuevo milenio es el trabajo "La revista Dimensión en el campo de la batalla de la cultura: 1956-1962”32. El objetivo aquí es "indagar en la experiencia de la revista Dimensión" refiriendo específicamente al análisis de "la situación continental" y "la tarea cultural" emprendidos por el proyecto editorial, en el contexto de las tradiciones intelectuales nacionales, antiguas y nuevas, que emergieron luego del golpe de Estado de 1955 al segundo gobierno de Juan Domingo Perón. Según se advierte, "Para comprender el surgimiento de Dimensión" es preciso "tener en cuenta la intención (política) de la revista de colocarse en un lugar de lectura de la realidad que no estaba siendo tenido en cuenta, o al menos no de modo mayoritario, en ese momento". Pues "las primeras lecturas luego del derrocamiento de Perón tuvieron como eje justamente el análisis de los aspectos negativos y positivos del desarrollo de ese gobierno, y un análisis crítico del mismo y muchas veces también de la historia argentina"33. En cambio, "las temáticas de la revista, y las maneras de indagarlas, giran centralmente alrededor del interior olvidado por el desarrollo del capitalismo". Aunque Santucho hace "aparecer las causas de dicha desigualdad en los tiempos de la colonia". Centra "allí el comienzo de este malestar, y, por lo tanto, de la urgente necesidad de reivindicar un regionalismo caracterizado por lo auténtico y natural, en franca contraposición con las ideas venidas de otras latitudes" 34 . Dimensión pone atención en la "idea de unidad continental subordinada al Occidente, que se reflejaría al interior del país creando sus propias subordinaciones, contradicciones y desigualdades" 35 . De ahí la apuesta central de la revista, desde el punto

\footnotetext{
${ }^{31}$ Santucho, op. cit., 29.

${ }^{3}$ Agustín Tillet, "La revista Dimensión en el campo de la batalla de la cultura: 1956-1962”, Actas VII Jornadas de Sociología de la Universidad Nacional de La Plata "Argentina en el escenario latinoamericano actual: debates desde las ciencias sociales", 5-7 de diciembre de 2012.

33 Tillet, op . cit., 7.

${ }^{34}$ Tillet, op . cit., 16.

${ }^{35}$ Tillet, op. cit., 18.

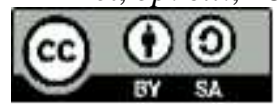


Roberto Remedi, De "militante" a "intelectual": Francisco René Santucho en el discurso de las ciencias humanas de los últimos quince años en Argentina / From "militant" to "intellectual": Francisco René Santucho in the discourse of the human sciences over the last fifteen years in Argentina, Revista Izquierdas, 27, abril 2016, ISSN 0718-5049, pp. 256-271

de vista de lo que entiende por su "tarea cultural" y en tanto "intelectuales", de "rescatar «lo propio» del olvido en que lo ha sumido la historia y el desarrollo" ${ }^{36}$. Sin duda es un aporte valioso destacar la singularidad del planteo de Dimensión y Santucho en el marco de las interpretaciones críticas de la realidad política y cultural elaboradas al nivel nacional durante el período inmediato al derrocamiento de Perón. Pero el planteo se queda en una concepción instrumental del discurso, como un conjunto de contenidos que deja ver claramente sus "intenciones". Además, desconoce los debates generados en el contexto particular de las tradiciones intelectuales de Santiago del Estero.

De este aspecto se ocupa precisamente la tesis de grado "Campo intelectual y campo político en Santiago del Estero. Orígenes de la nueva izquierda desde una matriz extracéntrica. Revista Dimensión y FRIP (1955-1965)"37. El trabajo parte de un diagnóstico: los estudios sobre los procesos de formación de la nueva izquierda en Argentina han concentrado su atención en experiencias de grupos políticos e intelectuales pertenecientes a la zona central del país, obviando caminos alternativos de incorporación al proceso de revisión de la izquierda tradicional. De ahí la propuesta de analizar "el proceso fundacional del PRT-ERP"38. Se explora en primera instancia el debate sobre la fecha de fundación y el fundador de la ciudad de Santiago del Estero acontecido en los primeros años de la década de 1950. De acuerdo con la descripción, Francisco René Santucho emergió en el ámbito intelectual en este momento, elaborando un discurso indigenista. Destacaba la gravitación del factor indígena presente en la provincia. Por entonces el discurso hegemónico local vinculaba estrechamente nación con catolicismo e hispanidad. En la segunda mitad de la década, Santucho lanza un proyecto editorial. La revista Dimensión aparece en el contexto posperonista. En la provincia, intelectuales católicos, socialistas y liberales, ligados a la gestión de la cultura dentro y fuera del Estado, elaboran distintos proyectos (como la creación de institutos de enseñanza superior), para modernizar los cuadros dirigentes y sacar a la provincia de la postergación. Pero el proyecto editorial de Santucho se articulaba "sobre una lectura del acontecer histórico regional en la cual, la dicotomía Interior-Buenos Aires representaría la dual cultura continental", esto es, indoamericana/europea. Premisa clave "para comprender la situación de atraso y postergación de la región y de la provincia" "39. Según este análisis, la revista se posiciona como "empresa dedicada enteramente al accionar cultural", apostando "por la autonomía del campo intelectual y por la libertad creadora de sus agentes". Lejos de ser un factor inhibidor este posicionamiento garantizaba "el pronunciamiento de un discurso crítico sobre la realidad local" 40 . No obstante esta apuesta "será abandonada, cuando en 1961 se funde el Frente Revolucionario Indoamericanista y Popular (FRIP)"41. La organización

\footnotetext{
${ }^{36}$ Tillet, op. cit., 19.

37 César D. Gómez, “Campo intelectual y campo político en Santiago del Estero. Orígenes de la nueva izquierda desde una matriz extracéntrica. Revista Dimensión y FRIP (1955-1965)”, Tesis de Grado, Licenciatura en Sociología, Facultad de Humanidades, Ciencias Sociales y de la Salud, Universidad Nacional de Santiago del Estero, 2013.

${ }^{38}$ Gómez, op. cit., 8.

${ }^{39}$ Gómez, op. cit., 80.

${ }^{40}$ Gómez, op. cit., 93.

${ }^{41}$ Gómez, op. cit., 94. 
Roberto Remedi, De "militante" a "intelectual": Francisco René Santucho en el discurso de las ciencias humanas de los últimos quince años en Argentina / From "militant" to "intellectual": Francisco René Santucho in the discourse of the human sciences over the last fifteen years in Argentina, Revista Izquierdas, 27, abril 2016, ISSN 0718-5049, pp. 256-271

adquiere un carácter "antiimperialista" primero y luego "marxista", por adscripción a los postulados del APRA-Alianza Popular Revolucionara Americana-Rebelde (1959), posteriormente convertida en Movimiento de Izquierda Revolucionaria (MIR)" "42. Más tarde el FRIP estrecha vínculos con la corriente trotskista Palabra Obrera para formar el Partido Revolucionario de los Trabajadores en 1965, adoptando una impronta "marxistaleninista" ${ }^{43}$. Con todo, en el trabajo existe un esfuerzo por reconstruir la posición de Santucho primero y luego de Dimensión con respecto a las acciones culturales y debates identitarios del contexto discursivo local (en torno a la fecha de fundación y el fundador de la ciudad de Santiago del Estero, a inicios de la década de 1950, y la creación de los institutos de enseñanza superior, hacia fines de la misma década, respectivamente). Sin duda constituye un aporte original. Sin embargo, el análisis sobre el "contexto discursivo" provincial más inmediato adquiere mayor prioridad que la indagación de la producción del propio Santucho, de la revista "cultural" y del grupo "político". A este respecto, precisamente porque falta un análisis más detallado sobre la específica mediación discursiva de estos tres aspectos ("Santucho", "Dimensión” y el "FRIP”) la hipótesis según la cual la lucha por autonomía del campo intelectual desde una revista "cultural" hacía posible un pronunciamiento crítico de la realidad en clave "indigenista-indoamericanista" no es del todo satisfactoria. No alcanza a dar cuenta por qué "posteriormente" el proyecto "cultural" (Dimensión) fue "abandonado" por una praxis explícitamente "política" (FRIP), siendo que el discurso político era visto por Santucho y su grupo como un factor "ideológico". Es decir, en qué medida, la des-articulación de un discurso "cultural" por un lado y "político" por el otro no se trató de un desdoblamiento discursivo de un momento (más que instancias sucesivas) promovido por los modos convencionales a través de los cuales (y los lugares comunes dónde) Dimensión y/o Santucho entendían implícitamente podían hablar de la "diferencia indígena".

\section{Francisco René Santucho, crítica, alteridad india/indígena, raza/etnicidad y polifonía}

La literatura dedicada a Francisco René Santucho en el ámbito de las ciencias humanas ha crecido considerablemente en los últimos quince años. Las primeras aproximaciones iniciaron el análisis de su figura, reconstruyendo su faceta "militante" a partir de sus acciones en el terreno "político". Pero después de la primera década del nuevo siglo los abordajes prefirieron indagar sobre su perfil "intelectual" prevalentemente a través del estudio de los proyectos "culturales" que animó. En este aspecto existió asimismo un avance en relación con el interés por indagar específicamente sobre su ejercicio profesional como "crítico". Sin embargo, aunque en diversos momentos Santucho fue estudiado considerando el ámbito dónde él mismo se inscribió, pocas veces ha recibido una atención como figura singular (M. A. Santucho). Francisco René aún es asimilado al espacio heterogéneo configurado en torno a Dimensión. En un sentido metodológico, uno y otro han sido objeto de una promiscuidad discursiva al ser tratados indistintamente (González,

\footnotetext{
${ }^{42}$ Gómez, op. cit., 96.

${ }^{43}$ Gómez, op. cit., 100.

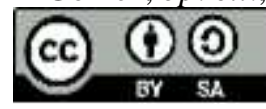


Roberto Remedi, De "militante" a "intelectual": Francisco René Santucho en el discurso de las ciencias humanas de los últimos quince años en Argentina / From "militant" to "intellectual": Francisco René Santucho in the discourse of the human sciences over the last fifteen years in Argentina, Revista Izquierdas, 27, abril 2016, ISSN 0718-5049, pp. 256-271

Gómez, Tillet). Sólo de modo muy atípico se ha reparado en la diversa naturaleza de ambos sujetos (Truco Dalmas). Asimismo, primó de forma implícita una idea de texto como espacio trasparente, una concepción del conocimiento como instrumento y una noción de sujeto autoconsciente. Excepcional y oblicuamente la producción de Francisco René Santucho fue vista como un espacio dialógico, fragmentario, estratificado, contradictorio, disperso y multitemporal (Grosso). Sin duda esta idea constituyó un avance significativo desde el punto de vista conceptual. Pero los posteriores estudios obviaron este antecedente y siguieron interrogando los aportes de Francisco René en el ámbito "intelectual” desde una concepción genérica. De ahí que ninguno de los trabajos haya podido plantear la pregunta por qué el propio Santucho prefirió definirse como crítico y no tan sólo como intelectual.

De manera que falta todavía un trabajo que centre la atención en la singularidad de Santucho como figura de la crítica en tanto lugar constituido en torno a un género discursivo. La crítica como ejercicio consciente emergió con "los tiempos modernos"”. Y "fue el romanticismo poético-filosófico - a fines del XVIII, en términos de ensayo sobre cultura y política- el que le imprimió a la modernidad el valor de una actualidad apremiante a descifrar" ${ }^{24}$. Desde entonces, el discurso crítico se configuró no como un género consagrado sino como una "escritura que irrumpe". El crítico "parte de la idea de que lo esencial no está dicho" o "sigue escondido en algún sótano de la realidad"45. Cuando Francisco René emergió en el ámbito de la producción intelectual de Santiago del Estero, a mediados de siglo XX, la crítica no era un territorio vacío. A principios de siglo XX, educadores, periodistas y abogados ya se habían constituido en agentes mediadores de muy distintas corrientes del pensamiento contemporáneo. El positivismo, el arielismo, el reformismo (vinculado con la Reforma Universitaria acontecida en la provincia de Córdoba en 1918), y distintos americanismos, encontraron en los integrantes de las diversas asociaciones profesionales sus flamantes intérpretes, y en las revistas literarias y culturales sus ámbitos de reinterpretación ${ }^{46}$. En este proceso la crítica fue reconfigurando su propio espacio de comunicación. Cabe preguntar entonces por las corrientes de pensamiento con las cuales Francisco René Santucho construyó el debate en términos conceptuales para fundar su afiliación al indoamericanismo, y en qué precisos modos, lugares y momentos promovió, en el contexto de su escritura, una representación de la "herencia indígena" como fundamento de la cultura nacional y continental.

Tal como indiqué más arriba, los trabajos disponibles concuerdan en destacar la impronta "indigenista" de las intervenciones políticas y culturales de Santucho. Señalan su adscripción al indoamericanismo en tanto reinterpretación del debate "político" de los años 1920 en torno al lugar de las naciones latinoamericanas dentro de la modernidad; más exactamente, los primeros posicionamientos de la Alianza Popular Revolucionaria Americana (APRA 1924), el movimiento social y político antiimperialista promovido por el líder peruano Víctor Raúl Haya de la Torre (1895-1979). Pero las reconstrucciones existentes no han propiciado todavía un enfoque antropológicamente informado con

\footnotetext{
${ }^{44}$ Nicolás Casullo, "El signo de la crítica y el arma de la palabra”, Rayando los confines, 2008.

${ }^{45}$ Casullo, op. cit., s. p.

${ }^{46}$ Héctor D. Guzmán, "Movimientos culturales en Santiago del Estero en el siglo XX. Los intelectuales y sus políticas de intervención cultural", Historia de las ideas en Santiago del Estero en el siglo XX, Gustavo Carreras y Héctor D. Guzmán (eds.), La Plata, Al margen, 2014, 219-245.
} 
Roberto Remedi, De "militante" a "intelectual": Francisco René Santucho en el discurso de las ciencias humanas de los últimos quince años en Argentina / From "militant" to "intellectual": Francisco René Santucho in the discourse of the human sciences over the last fifteen years in Argentina, Revista Izquierdas, 27, abril 2016, ISSN 0718-5049, pp. 256-271

relación a las específicas variables intervinientes en el proceso de construcción del singular objeto de la praxis crítica indoamericanista de Francisco René: la alteridad india/indígena. Las aproximaciones examinadas trabajaron hasta ahora con una noción genérica y atemporal de la raza y la etnicidad (y de manera implícita), haciendo prevalecer además (y también tácitamente) una concepción teórica del objeto en la perspectiva de sujeto moderno. Falta entonces un análisis que tenga en cuenta el lugar de ese debate "político" dentro de las explicaciones de las semejanzas y las diferencias "culturales" elaboradas en el continente durante el período, y la ideología que las fundó, esto es, el mestizaje o el diálogo político -tácito o manifiesto- acontecido en Latinoamérica sobre la creencia en la conveniencia, posibilidades, condiciones y modos de la asimilación de los pueblos "nativos" al estilo de vida "civilizada" 47 , o los variados proyectos de blanqueamiento que tuvieron lugar en el subcontinente promoviendo particulares maneras de concebir la "alteridad india/indígena", mediante nociones singulares de "raza" y/o "etnicidad", o de diferencias en la "naturaleza" y/o la "cultura", de manera tácita o explícita, y en relación asimétrica con comunidades superordinadas como el "estado-nación", la "colonia", la "cristiandad", la "modernidad", etc., en concretas tradiciones culturales, contextos políticos y económicos, geográficos y temporales ${ }^{48}$.

Señalé en otra parte, la referencia a la "otredad indígena" en la crítica literaria elaborada por Santucho desde su visión indoamericana en el contexto particular de Santiago del Estero a mediados de siglo XX tenía características determinadas ${ }^{49}$. Es lo que deja ver su lectura de Shunko (1949), la novela del escritor comprovinciano Jorge Washington Ábalos. Ciertamente, la reivindicación de la "alteridad india" no carecía de determinaciones en el texto mismo de la obra. En el relato un maestro retoma un diálogo epistolar con un niño diciendo "Querido Chango". El maestro vive en la ciudad. Shunko habita un pequeño poblado. Ellos rememoran experiencias compartidas en torno a una escuela rural de Santiago del Estero. Según el crítico santiagueño la novela es una reflexión sobre la "dualidad cultural" existente en la provincia y posee un "valor etnológico" claro y actual. El mismo Ábalos había expresado su intención de tematizar la "diferencia cultural". Pero en la creación literaria el término "chango" no nombra una niñez genérica. En el uso del término se implican connotaciones étnicas y raciales, descripciones de "costumbres" y de características "físicas". Entonces la alteridad ("indígena") es construida de manera eufemística ("chango"). De modo que, la reivindicación de la "diferencia cultural" realizada por Santucho en su crítica de la novela de Ábalos es una reflexión subrepticia sobre los prejuicios raciales. Pero el cuestionamiento al racismo sólo es posible a través de

\footnotetext{
${ }^{47}$ Marisol de la Cadena, “Son los mestizos híbridos? Las políticas conceptuales de las identidades andinas”, Universitas Humanística 61, Bogotá-Colombia, enero-junio de 2006, 51-84.

${ }^{48}$ Claudia Briones, "Formaciones de alteridad: contextos globales, procesos nacionales y provinciales", Cartografías argentinas. Políticas indigenistas y formaciones provinciales de alteridad, Claudia Briones (ed.), Buenos Aires, Antropofagia, 2005, 25, Claudia Briones, La alteridad del "cuarto mundo". Una deconstrucción antropológica de la diferencia, Buenos Aires, Ediciones del Sol, 1998, 207-8, Claudia Briones, "Mestizaje y blanqueamiento como coordenadas de aboriginalidad y nación en Argentina", Runa 23, Buenos Aires-Argentina, 2002, 67.

${ }^{49}$ Roberto A. Remedi, "Indoamericanismo y mestizaje en la crítica de Francisco René Santucho: su lectura de Shunko". A Contracorriente. Revista de historia social y literatura de América Latina 12: 2, North Carolina State, Winter 2015, 101-139.
}

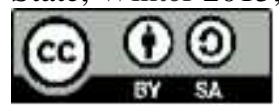


Roberto Remedi, De "militante" a "intelectual": Francisco René Santucho en el discurso de las ciencias humanas de los últimos quince años en Argentina / From "militant" to "intellectual": Francisco René Santucho in the discourse of the human sciences over the last fifteen years in Argentina, Revista Izquierdas, 27, abril 2016, ISSN 0718-5049, pp. 256-271

una reflexión impregnada de vocabulario culturalista. En el texto, la comprensión de la "raza" (en tanto características biológicas) y la "etnicidad" (como conjunto de costumbres) no coinciden con el uso convencional de nominar a tales fenómenos: "cultura" podía significar "naturaleza". Dichas torsiones de la escritura (y el entendimiento) constituían una condición de posibilidad de la praxis indoamericanista, pero también un obstáculo en cuanto contribuían a dejar en suspenso toda puesta en evidencia de la actualidad y eficacia del discurso racista ${ }^{50}$. Con todo, el análisis de la producción y perspectiva indoamericana de Santucho reclama una atención más aguda sobre la singularidad de su actividad crítica (en tanto práctica que reivindicó explícitamente ante sus pares "intelectuales") y su particular concepción de la alteridad india/indígena u "otros raciales/étnicos", atendiendo a la historicidad y polifonía de toda praxis discursiva.

\section{Bibliografía}

Bajtín, Mijaúl. Estética de la creación verbal. Buenos Aires: Siglo XXI Editores, 2002.

Briones, Claudia. "Formaciones de alteridad: contextos globales, procesos nacionales y provinciales". Cartografías argentinas. Políticas indigenistas y formaciones provinciales de alteridad. Claudia Briones (ed.). Buenos Aires: Antropofagia, 2005. 9-36.

Briones, Claudia. La alteridad del "cuarto mundo". Una deconstrucción antropológica de la diferencia. Buenos Aires: Ediciones del Sol, 1998.

Briones, Claudia. "Mestizaje y blanqueamiento como coordenadas de aboriginalidad y nación en Argentina". Runa 23, Buenos Aires-Argentina, 2002: 61-88. http://revistascientificas.filo.uba.ar/index.php/runa/article/view/1299/1252. Edición en línea. 12 de junio de 2015.

Cadena, Marisol de la. “¿Son los mestizos híbridos? Las políticas conceptuales de las identidades andinas". Universitas Humanística 61, Bogotá-Colombia, enero-junio de 2006: 51-84. http://revistas.javeriana.edu.co/index.php/univhumanistica/article/viewFile/2075/1315. Edición en línea. 29 de enero de 2014.

Carnovale, Vera. Los combatientes. Historia del PRT-ERP. Buenos Aires: Siglo XXI Editores, 2011.

Casullo, Nicolás. "El signo de la crítica y el arma de la palabra". Rayando los confines (2008). http://www.rayandolosconfines.com.ar/reflex63_casullo.html. Edición en línea. 3 de noviembre de 2012.

\footnotetext{
${ }^{50}$ Remedi, op. cit., 134.
} 
Roberto Remedi, De "militante" a "intelectual": Francisco René Santucho en el discurso de las ciencias humanas de los últimos quince años en Argentina / From "militant" to "intellectual": Francisco René Santucho in the discourse of the human sciences over the last fifteen years in Argentina, Revista Izquierdas, 27, abril 2016, ISSN 0718-5049, pp. 256-271

Ehrlich, Laura. "Santucho, Francisco René". Diccionario biográfico de la izquierda argentina. De los anarquistas a la "nueva izquierda" (1870-1976). Horacio Tarcus (dir.). Buenos Aires: Emecé Editores, 2007. 605-608.

Gómez, César D. "Apuntes sobre la revista, el grupo y la libraría Dimensión. La cultura como incitación”. Políticas de la memoria 14, Buenos Aires-Argentina, verano de 2013-2014: 118-123.

Gómez, César D. "Campo intelectual y campo político en Santiago del Estero. Orígenes de la nueva izquierda desde una matriz extracéntrica. Revista Dimensión y FRIP (1955-1965)". Tesis de Grado, Licenciatura en Sociología. Facultad de Humanidades, Ciencias Sociales y de la Salud, Universidad Nacional de Santiago del Estero, 2013.

González, Horacio. "Dimensión: el paso restante". Dimensión. Revista de cultura y crítica. Edición facsimilar. Santiago del Estero: Subsecretaría de Cultura de la Provincia de Santiago del EsteroBiblioteca Nacional de la República Argentina, 2012. 9-10.

Grosso, José L. "Añoranza y revolución. Lo indio, lo negro y lo cholo en lo «santiagueño», en el norte argentino". Páginas de cultura 6, Cali-Colombia, septiembre de 2011: 32-41.

Guzmán, Héctor D. "Movimientos culturales en Santiago del Estero en el siglo XX. Los intelectuales y sus políticas de intervención cultural". Historia de las ideas en Santiago del Estero en el siglo XX. Gustavo Carreras y Héctor D. Guzmán (eds.). La Plata: Al margen, 2014. 219-245.

Pozzi, Pablo. Por las sendas argentinas: PRT-ERP, la guerrilla marxista. Buenos Aires: Imago Mundi, 2004. http://es.scribd.com/doc/26487398/Pablo-Pozzi-Por-Las-Sendas-Argentinas-El-PRTERP-y-La-Guerrilla-Marxista/. Edición en línea. 15 de marzo de 2014.

Remedi, Roberto A. "Indoamericanismo y mestizaje en la crítica de Francisco René Santucho: su lectura de Shunko". A Contracorriente. Revista de historia social y literatura de América Latina 12: 2, North Carolina State, Winter 101-139. http://acontracorriente.chass.ncsu.edu/index.php/acontracorriente/article/view/1270. Edición en línea. 6 de julio de 2015 .

Santis, Daniel de. La historia del PRT-ERP: por sus protagonistas. Temperley-Estación Finlandia: A formar filas-Editora guevarista, 2010.

Santucho, Blanca R. Nosotros, los Santucho. Buenos Aires: el autor, 2009.

Santucho, Luis H. "Francisco René Santucho". La unidad indoamericana. Buenos Aires: Populibros, 2009. 7-27.

Santucho, Mario A. "Las intuiciones de un «cacique» del siglo XX. Apuntes sobre el pensamiento de Francisco René Santucho”. Dimensión. Revista de cultura y crítica. Edición facsimilar. Santiago del Estero: Subsecretaría de Cultura de la Provincia de Santiago del Estero-Biblioteca Nacional de la República Argentina, 2012. 21-35.

Seoane, María. Todo o nada. La historia secreta y la historia pública del jefe guerrillero Mario Roberto Santucho. Editorial Sudamericana: Buenos Aires, [1991] 2009. 
Roberto Remedi, De "militante" a "intelectual": Francisco René Santucho en el discurso de las ciencias humanas de los últimos quince años en Argentina / From "militant" to "intellectual": Francisco René Santucho in the discourse of the human sciences over the last fifteen years in Argentina, Revista Izquierdas, 27, abril 2016, ISSN 0718-5049, pp. 256-271

Tarcus, Horacio. "Introducción”. Diccionario biográfico de la izquierda argentina. De los anarquistas a la "nueva izquierda" (1870-1976). Horacio Tarcus (dir.). Buenos Aires: Emecé Editores, 2007. XI-XXX.

Tasso, Alberto. "Dimensión y la relectura de la historia". Dimensión. Revista de cultura y crítica. Edición facsimilar. Santiago del Estero: Subsecretaría de Cultura de la Provincia de Santiago del Estero-Biblioteca Nacional de la República Argentina, 2012. 11-19.

Tillet, Agustín. "La revista Dimensión en el campo de la batalla de la cultura: 1956-1962". Actas VII Jornadas de Sociología de la Universidad Nacional de La Plata "Argentina en el escenario latinoamericano actual: debates desde las ciencias sociales", 5-7 de diciembre de 2012. http://jornadassociologia.fahce.unlp.edu.ar/actas/Tillet.pdf/view?searchterm=None. Edición en línea. 3 de abril de 2014.

Trucco Dalmas, Ana B. M. "Santiago del Estero 1956-1962. Dimensión, una revista de cultura y crítica”. Políticas de la memoria 14, Buenos Aires-Argentina, verano de 2013-2014: 124-129. 